\title{
ALEITAMENTO MATERNO E A OCORRÊNCIA DO DESMAME PRECOCE EM PUÉRPERAS ADOLESCENTES
}

\author{
BREASTFEEDING AND THE OCCURRENCE OF EARLY WEANING AMONG ADOLESCENT MOTHERS
}

\author{
Danielle da Costa Souto ${ }^{1 *}$, Márcia Elisa Jager ${ }^{2 *}$, Ana Cristina Garcia Dias ${ }^{3^{*}}$ \\ 1'daniellessouto@hotmail.com, ${ }^{2}$ marciajager@yahoo.com.br, ${ }^{3}$ anacristinagarciadias@gmail.com \\ *Universidade Federal de Santa Maria (UFSM)
}

Data de entrada do artigo: 26/05/2013

Data de aceite do artigo: 19/03/2014

\section{RESUMO}

Objetivos: Refletir sobre o fenômeno da amamentação no contexto da maternidade adolescente, identificando fatores capazes de influenciar na ocorrência do desmame precoce. Materiais e Métodos: Realizou-se uma revisão narrativa de literatura, e a discussão teórica organizou-se em dois eixos temáticos: (1) Fatores que influenciam na qualidade da amamentação adolescente; (2) Fatores que contribuem para a ocorrência do desmame precoce. Resultados: No eixo um, destacam-se: situação conjugal da mãe adolescente, o apoio familiar e as informaçóes fornecidas pela equipe de saúde sobre o aleitamento materno, além de seus benefícios para a mãe e para o bebê. No eixo dois, ressalta-se: o relacionamento conjugal, a introdução de alimentos e líquidos durante o período em que se recomenda somente a amamentaçáo exclusiva e a falta ou sobrecarga de informações em relação à prática. Conclusões: É necessária a conscientização das mães adolescentes sobre as vantagens da amamentação e as desvantagens do desmame precoce para o desenvolvimento físico e psíquico do lactente. Os profissionais de saúde devem orientar as mães e incentivar o aleitamento materno através de um discurso claro e objetivo, direcionado aos diferentes contextos socioculturais nos quais as máes encontram-se inseridas.

Palavras-chave: aleitamento materno; adolescente; desmame; revisão.

\section{ABSTRACT}

Objective: To reflect on the phenomenon of breastfeeding in the context of adolescent motherhood, identifying factors that influence the occurrence of early weaning. Materials and Methods: We conducted a narrative review of the literature, and theoretical discussion was organized into two main themes: (1) Factors that influence the quality of adolescent breastfeeding; (2) Factors contributing to the occurrence of early weaning. Results: On the first theme, we highlight: marital status of the adolescent mother, family support and information provided by the health staff on breastfeeding, in addition to its benefits for mother and baby. On the second theme, marital relationship, the introduction of food and fluids during the period in which only breastfeeding is recommended and the lack or overload of information regarding this practice are emphasized. Conclusions: The awareness of adolescent mothers about the benefits of breastfeeding and the disadvantages of early weaning for the physical and mental development of infants is needed. Healthcare professionals should guide them and encourage breastfeeding through a clear and objective discourse, directed to different social and cultural contexts in which mothers are inserted.

Keywords: breastfeeding; adolescent; weaning; review. 


\section{Introdução}

Frequentemente, a gravidez e maternidade na adolescência são percebidas como um problema de saúde públi$\mathrm{ca}$, uma vez que se associam a riscos biológicos tanto para o desenvolvimento da adolescente quanto para o do bebê $\hat{e}^{1,2}$. Estudos têm se preocupado em discutir fatores que tornam adolescentes vulneráveis à gestação e as implicaçóes que a gravidez e a maternidade podem trazer para as vidas das adolescentes, bebês e seus familiares ${ }^{1,3-5}$ Porém, fenômenos como a amamentação natural (através do seio materno), que acompanham o processo de maternidade, ainda são pouco investigados. Isto pode ser constatado pelas autoras desse trabalho ao realizarem um levantamento de pesquisas sobre amamentação adolescente publicadas no Banco de Teses da Capes no período de 1997 a 2010. Através do cruzamento das palavras "amamentação" e "adolescência", encontraram 22 resumos referentes ao tema, mas, entre esses trabalhos, identificaram-se apenas seis pesquisas que se direcionavam diretamente à temática da amamentação durante a adolescência. Nesse sentido, considera-se que ainda são escassos os estudos que reconhecem a importância da amamentação, especialmente quando essa acontece na adolescência, subestimando a influência psíquica e biológica do aleitamento materno para a saúde da mãe e do bebê.

A amamentação é uma das principais formas de contribuição para o desenvolvimento e crescimento da criança, devendo ser mantida, pelo menos, até os seis meses de vida do bebê $\hat{e}^{6}$ Isto se deve ao fato de o leite humano possuir um valor nutricional superior a qualquer outro tipo de leite, funcionando como fonte de alimento e de proteção contra doenças. Além disso, o ato de prover o leite ao bebê através do seio materno promove a formação do vínculo afetivo entre a mãe e o filho ${ }^{7} \mathrm{~A}$ formação do vínculo entre mãe e bebê é um dos principais benefícios da amamentação, tendo em vista sua capacidade de proporcionar uma interação rica entre os dois, capaz de gerar sensaçóes de prazer e satisfaçáo. Pesquisas neurobiológicas apontam que estas sensaçóes são resultados de alteraçóes hormonais do corpo materno durante a amamentação. Por exemplo, o hormônio ocitocina, liberado pelo organismo materno quando o bebê entra em contato ou massageia o seio da mãe, provoca sonolência leve, euforia e aumento de tolerância à dor fortalecendo assim seu vínculo afetivo Alguns neurofisiologistas também afirmam que os elevados níveis de ocitocina liberados, acompanhado pela prolactina (hormônio que estimula a produção de leite pelas glândulas mamárias e o aumento das mamas) colaboram para o aumento do amor materno e, consequentemente, para formação deste vínculo ${ }^{8}$.

Entretanto, apesar de algumas pesquisas apontarem os benefícios biológicos e psíquicos da amamentação, tanto para a mãe quanto para o bebê, ainda é comum a ocorrência do desmame precoce. $\mathrm{O}$ desmame precoce acontece quando a mãe deixa de amamentar seu filho antes dos seis meses de idade, período no qual é recomendada a amamentação como forma exclusiva de alimentação do bebề. De fato, muitas mães amamentam seus filhos durante quatro ou seis meses de idade, porém um número crescente de mulheres muda para a alimentação artificial após poucas semanas de vida do bebê. Desta maneira, o leite materno está sendo substituído, cada vez mais cedo, pela mamadeira e por suplementos alimentares ${ }^{10}$.

No contexto da maternidade adolescente, uma pesquisa realizada por Frota e Marcopito ${ }^{11}$ constatou que mães adolescentes amamentam durante menos tempo seus filhos quando comparadas às mães adultas, por causa de diversos fatores, como a existência ou não de vida conjugal e o retorno à vida escolar. De fato, esses, entre outros fatores, podem contribuir para a ocorrência do desmame precoce. É importante compreender a visão dos profissionais que trabalham com as mães adolescentes, pois é através de pesquisas que são abordadas e identificadas as facilidades e dificuldades deste público em relação à amamentação e ao desmame precoce. Ao serem percebidos esses aspectos, é possível que as políticas públicas repensem seus programas de incentivo à amamentação e os profissionais de saúde reflitam sobre sua prática. Através disso, pode ser possível oferecer maior suporte às mães adolescentes, que passam pela gravidez e pelo período de amamentação em uma fase peculiar de suas vidas. O objetivo desse trabalho é identificar a visão de alguns pesquisadores sobre os fatores capazes de influenciar na amamentação e na ocorrência do desmame precoce no contexto da maternidade adolescente.

\section{Metodologia}

Foi realizada uma revisão narrativa de literatura sobre aleitamento materno em mães adolescentes e a ocorrência do desmame precoce. Este tipo de revisão apresenta uma temática mais aberta, onde dificilmente se parte de uma questão específica bem definida, não exigindo um protocolo rígido para sua confecção. A busca das fontes de dados não é predeterminada e específica, sendo frequentemente menos abrangente. A seleção dos artigos é arbitrária, fornecendo ao autor informaçôes sujeitas ao viés de seleção, com grande interferência da percepção subjetiva. Esta não apresenta as fontes de informação utilizadas, a metodologia para busca das referências, nem os critérios utilizados na avaliação e seleção de trabalhos ${ }^{12}$.

Optou-se por este tipo de revisão bibliográfica porque o objetivo central do trabalho não é apresentar um 
panorama sobre o assunto, mas desenvolver uma reflexão sobre a problemática da amamentação na adolescência, identificando alguns fatores de risco e proteção para a ocorrência do desmame precoce. A discussáo foi organizada a partir de dois eixos temáticos: (1) Fatores que influenciam na qualidade da amamentação adolescente; (2) Fatores que contribuem para a ocorrência do desmame precoce. Delinearam-se estes eixos temáticos para nortear a discussáo sobre os fatores de risco e de proteçáo relacionados à prática da amamentação e à ocorrência do desmame precoce no contexto da maternidade adolescente.

\section{Fatores que Influenciam na qualidade da amamentação adolescente}

A amamentação na adolescência é influenciada por diferentes fatores. $\mathrm{O}$ apoio familiar recebido e o conhecimento sobre técnicas de amamentação, posições, massagens no seio para estimular o leite e a aquisiçáo de experiência anterior são fatores que contribuem para a ocorrência da amamentaçáo e são capazes de evitar o desmame precoce. Orientaçóes sobre o aleitamento materno são repassadas frequentemente às mães no ambiente hospitalar por profissionais de saúde que realizam o pré-natal ou que acompanham o processo de nascimento do bebế ${ }^{13}$.

De fato, os dias de permanência no hospital, após o parto, e as informaçóes sobre amamentação fornecidas neste local são fatores capazes de influenciar na prática da amamentação. A importância do atendimento, ainda em ambiente hospitalar, pode ser confirmada no estudo realizado por Frota e Marcopito ${ }^{11}$, na cidade de Montes Claros, Minas Gerais, com 237 mães adolescentes e 239 mães adultas. $\mathrm{O}$ estudo avaliou os fatores relacionados à ocorrência do desmame precoce e aqueles capazes de contribuir para a continuidade da amamentação e encontrou que os principais problemas na lactação tendem a surgir nas primeiras semanas pós-parto. Isto evidencia que o auxílio especializado prestado pelos profissionais de saúde neste momento pode contribuir de forma positiva para a prática da amamentação ${ }^{11}$. De fato, a relevância do atendimento especializado neste período pós-parto é um ponto importante, mas também é necessário destacar que a assistência ao aleitamento materno adolescente não deve ser interrompida após a saída do hospital. É necessário que os atendimentos e as informações sobre amamentação sejam estendidos às casas das adolescentes através de atendimentos domiciliares com o intuito de proporcionar um melhor acompanhamento do processo de aleitamento materno após a alta hospitalar ${ }^{13,14}$.

Neste sentido, destaca-se a relevância de informaçóes sobre o aleitamento materno e sua influência positiva na prática da amamentação adolescente. É importante dizer que estas informaçóes podem ser transmitidas às mães através de diferentes estratégias. Um estudo sobre a prática da amamentaçáo, realizado em uma maternidade de Ribeiráo Preto, Sáo Paulo, por Camarotti, Nakano, Pereira, Medeiros e Monteiro ${ }^{14}$, apontou que as 80 adolescentes puérperas participantes receberam orientaçôes sobre amamentação em consultas pré-natais e cursos oferecidos para gestantes em postos de saúde e hospitais. Já outro estudo sobre a mesma prática, realizado por Nunes, Oliveira e Vieira ${ }^{15}$ em uma Unidade Básica de Saúde em Sobral, Ceará, traz que, além de receberem informaçóes sobre aleitamento materno em consultas pré-natais, as sete puérperas adolescentes participantes também obtiverem conhecimentos sobre o assunto por meio de palestras, cartazes e com familiares e amigas.

Os profissionais de saúde são uma importante fonte de informação para as mães, mas parecem existir problemas nesta comunicação. Chama-se atenção para a qualidade das informaçóes sobre amamentação e os conhecimentos sobre aspectos nutricionais e biológicos repassados pelos profissionais da saúde. Estes não têm sido suficientes para promover uma atitude materna favorável à prática adequada de aleitamento materno. Para que isto ocorra, é necessário que os profissionais, além da transmissão dos benefícios nutricionais e biológicos, também valorizem e transmitam para as mães os benefícios psicológicos do aleitamento materno para a construção do vínculo entre mãe e bebê. Da mesma forma, deve existir um reconhecimento das dificuldades encontradas pelas mulheres durante a amamentação, como a ocorrência de fissura mamilar. Isto pode fazer que elas se sintam compreendidas quando o ato de amamentar causar dor e/ou desconforto. Reconhecer as dificuldades que podem perpassar a amamentação também é importante, pois ao conhecê-las é possível preveni-las, diminuindo a sua ocorrência. Através destes comportamentos por parte dos profissionais, é possível que as mães se sintam apoiadas nos serviços de saúde os quais frequentam e seguras para procurar o atendimento especializado diante de possíveis dificuldades de amamentar. Isto também pode diminuir a ocorrência do desmame precoce, na medida em que existem profissionais que apoiam e incentivam a prática do aleitamento materno e o percebem como capaz de influenciar na saúde física e psíquica tanto da mãe quanto do bebê $\hat{e}^{16,17}$.

Um profissional capaz de contribuir no atendimento à puérpera é o psicólogo, na medida em que se faz presente na equipe de atendimento interdisciplinar oferecido às mulheres. Este, em pareceria com médicos e enfermeiros, pode ajudar a mãe-nutriz a compreender as orientaçôes médicas sobre os benefícios físicos e salientar os benefícios psicológicos presentes na prática do 
aleitamento materno. Dessa forma, o psicólogo, com uma equipe multidisciplinar, se torna responsável pelo sucesso da amamentação, tentando evitar problemas que poderiam levar ao desmame precoce ${ }^{18,19}$.

De fato, os problemas na comunicação sobre informaçôes relacionadas à amamentação decorrem, na maioria das vezes, do despreparo de alguns profissionais da saúde em orientar as mães. Isto pode ser confirmado através de um estudo realizado por Demitto, Silva, Páschoa, Mathias e Bercinii ${ }^{20}$, com 55 enfermeiros e 34 médicos atuantes na rede pública de saúde de São Paulo. $\mathrm{O}$ estudo investigou o desempenho destes profissionais quanto ao nível de conhecimentos sobre amamentação e as práticas de incentivo que utilizavam. Os resultados apontaram que os profissionais tinham conhecimentos sobre a composição do leite humano e seu valor nutricional para o bebê, bem como sobre o momento certo de sugerir a interrupção da amamentação em casos de risco à mãe ou ao bebê. Entretanto, não sabiam orientar corretamente quanto às posiçóes adequadas para amamentar, frequência e duraçáo das mamadas. De fato, os profissionais investigados apresentaram pouco conhecimento sobre as dificuldades encontradas pelas mulheres durante a amamentação e pareciam conhecer pouco, inclusive, sobre os benefícios do aleitamento materno para o desenvolvimento físico e psíquico da mãe e do bebê.

Este aspecto também é retratado em uma pesquisa realizada por Kohler ${ }^{21}$ em Porto Alegre, Rio Grande do Sul, com 15 adolescentes puérperas. Nesta pesquisa, constatou-se que, com frequência, alguns profissionais de saúde orientam as mães adolescentes a introduzirem alimentação artificial antes de esgotarem todas as possibilidades de manter a criança em aleitamento materno exclusivo. Isto acontece porque alguns destes profissionais frequentemente não se interessam em saber quais dificuldades estão sendo encontradas pelas mães. Ao serem surpreendidos pela resistência da mãe em amamentar, logo sugerem a introdução de outros alimentos e, por vezes, até a suspensão da amamentação. Uma alternativa para evitar este tipo de comportamento dos profissionais de saúde que trabalham no atendimento às gestantes e puérperas é oportunizar cursos de capacitação e educação continuada sobre aspectos relacionados à amamentação ${ }^{22}$, como a duração e a frequência correta das mamadas e os cuidados básicos com a mama ${ }^{20}$.

Observa-se que a maioria dos aspectos levantados ao longo deste primeiro eixo temático pode influenciar diretamente na manutenção, duração e na qualidade da amamentação realizada por mães adolescentes. Muitos deles contribuem diretamente para a interrupção da amamentaçáo e acabam ocasionando o desmame precoce.

\section{Fatores que contribuem para a ocorrência do desmame}

$\mathrm{Na}$ amamentação realizada por adolescentes, o principal fator que causa o desmame precoce está relacionado à queixa sobre a falta de leite ou que o leite está enfraquecido. $\mathrm{O}$ uso desses argumentos pode ocasionar a suspensão da amamentação logo nas primeiras semanas de vida do bebê. Outros fatores ainda são levados em consideração para a ocorrência do desmame precoce na adolescência, como a baixa escolaridade e o baixo nível socioeconômico da mãe, a desnutrição materna e o curto período de acompanhamento pré-natal ${ }^{23}$.

O acompanhamento pré-natal é uma intervenção essencial para a saúde da mãe e do bebê. Através dele é possível que a gestante adquira conhecimentos sobre os benefícios da amamentação, o que evitaria o desmame precoce ${ }^{23}$. Quando o pré-natal acontece de forma precária ou por um período de tempo menor do que o recomendado pelo Ministério da Saúde, pode prejudicar a saúde da gestante e do bebê. $\mathrm{O}$ acompanhamento pré-natal deve iniciar já no primeiro trimestre gestacional, sendo que as consultas de acompanhamento devem persistir durante toda a gravidez, acompanhadas por orientaçóes referentes à gestação, amamentação e saúde da mãe e do bebê. Neste sentido, devem ser fornecidas à gestante e aos demais familiares interessados orientaçōes sobre o preparo das mamas, técnicas para estimular a produção de leite e instruções que incentivam a prática do aleitamento materno durante o período dos seis primeiros meses de vida do bebêt $\hat{A}^{24}$.

Entretanto, apesar de reconhecer a importância do acompanhamento pré-natal para sua saúde e do bebê, muitas mães adolescentes não o realizam de forma adequada. Isto acontece em decorrência do receio que algumas adolescentes podem ter em assumir publicamente uma gravidez ${ }^{21}$. A gravidez na adolescência, na maioria das vezes, é vista socialmente como uma experiência precoce, na qual perdura a crença de que a adolescente não possui condiçóes físicas, psíquicas, sociais e econômicas para exercer a maternidade de maneira a oferecer um ambiente familiar adequado para o desenvolvimento infantil ${ }^{1,2}$. A maternidade adolescente pode estar associada a inúmeras perdas concretas e subjetivas, como a do senso de identidade, a da confiabilidade da família, a das expectativas futuras (que devem ser reformuladas), a do companheiro e da proteçáo familiar. Essas perdas podem trazer repercussóes emocionais negativas, que podem levar a adolescente a um processo de somatização psicológica, com sinais e/ou sintomas que podem pôr em risco a gestação saudável ${ }^{25}$. Somado a isto, o receio do preconceito pode fazer que algumas adolescentes não procurem um acompanhamento prénatal adequado, estando mais vulneráveis à ocorrência 
do desmame precoce, uma vez que podem não reconhecer a importância da prática da amamentação para o desenvolvimento físico e psíquico de seu bebê $\hat{e}^{21}$.

Além dos impactos da falta ou do inadequado acompanhamento pré-natal na prática da amamentação adolescente, outros fatores são capazes de influenciar na ocorrência do desmame precoce. Por exemplo, muitas mães desmamam seus filhos por problemas relacionados à mama, como a presença de dor e fissura mamilar ${ }^{13}$. Outras mães o fazem por não conseguirem atribuir um significado pessoal à amamentação ou ainda por não reconhecerem os benefícios do aleitamento materno para si e para o bebê. Além disso, o incentivo por parte das mães das adolescentes para a introdução de outros alimentos e líquidos, principalmente chás e água, no período de aleitamento materno exclusivo, também aparece como um fator que estimula o desmame precoce ${ }^{26}$.

Mais um aspecto capaz de influenciar na ocorrência do desmame precoce é a existência ou não de vida conjugal das máes adolescentes e o retorno à escola. Mães adolescentes que mantiveram o relacionamento conjugal após o nascimento dos filhos podem realizar o desmame mais cedo do que as estão sem um parceiro. Isto acontece por causa do retorno da vida sexual, envolvendo questóes referentes à sexualidade de cada casal. Da mesma forma, o retorno à escola após o parto pode contribuir para a ocorrência do desmame precoce. As avós ou as próprias adolescentes podem começar a inserir outros alimentos e líquidos para suprir a falta do leite materno durante o período escolar ${ }^{11}$.

Outros motivos que influenciam na ocorrência do desmame precoce também são trazidos pela literatura: o retorno a rotina de trabalho e o "não gostar de amamentar". O retorno à rotina de trabalho contribui para o desmame precoce quando as mães sentem a necessidade de retornar a suas atividades profissionais, devido às dificuldades financeiras. Lembramos que muitas mães adolescentes já podem se encontrar inseridas no mercado de trabalho ao engravidarem, desta forma, assim que termina o período de licença maternidade, devem retornar às atividades, deixando a amamentação de lado por náo conseguirem cumprir o período de aleitamento recomendado. Além disso, os sentimentos de desprazer relacionados à amamentação, experienciados por algumas mulheres, podem explicar a expressão "não gostar de amamentar". Algumas mães adolescentes multíparas, por exemplo, que passaram por experiências malsucedidas de amamentação, podem relacioná-las a sentimentos e experiências negativas, como dores decorrentes de fissuras mamilares, ocorrência de leite empedrado etc. ${ }^{14}$

Outro fator apontado pela literatura consultada como relevante ao processo de amamentação bem sucedido e que pode evitar a ocorrência do desmame precoce é a participação paterna. Quando o pai tem conhecimento sobre os benefícios que o aleitamento materno pode trazer para o desenvolvimento infantil e para o vinculo entre mãe e bebê, ele se torna capaz de incentivar a mulher a amamentar, apoiando-a em situaçóes de desconforto geradas, por exemplo, na ocorrência de fissuras mamilares. Entretanto, alguns desafios culturais se colocam perante a possibilidade da participação paterna. Um deles é a ausência de serviços e programas de saúde que incluam os pais no processo grávido-puerperal. Essa ausência dificulta a participação destes em consultas pré-natais, em orientaçóes sobre aleitamento materno ou sobre o desenvolvimento da criança ${ }^{15,27-29}$.

Salienta-se que é exatamente durante as consultas do acompanhamento pré-natal que o pai teria um papel importante. Ao participar deste acompanhamento, o casal pode obter esclarecimentos sobre o aleitamento materno e, desta forma, o homem compreenderia melhor os benefícios desta prática para o bebê e a importância da amamentação na formação do vínculo e desenvolvimento afetivo da criança. Quando o homem começa a se perceber como pai, é essencial que ele possa compreender as modificaçôes que ocorrem na dinâmica familiar com a vinda do bebê. A partir disso, ele poderá melhorar sua participação nos cuidados da criança e ajudar à esposa no período da amamentaçáo. Essas atitudes serão importantes para o sucesso da prática do aleitamento materno ${ }^{27,30}$.

Faz-se importante ainda destacar que a maneira de perceber a maternidade adolescente pode dificultar o processo de amamentação e aumentar a probabilidade da ocorrência do desmame precoce. Algumas vezes, mães adolescentes recebem rótulos preconcebidos sobre a própria incapacidade de cuidar do filho, em função das características presentes na adolescência, a exemplo do egocentrismo e dos problemas de autoimagem ${ }^{14}$. Neste sentido, os profissionais de saúde precisam estar capacitados para acolher a adolescente, onde palavras de julgamento ou críticas, mesmo veladas, podem representar mau acolhimento por parte dos profissionais. Com isso, algumas adolescentes podem sentir receio de procurar os serviços de saúde, dificultando o acesso ao atendimento. No entanto, quando bem acolhidas, os serviços tendem a favorecer a procura de cuidados gestacionais e puerperais quando necessário, ajudando as adolescentes a superarem riscos da gestação, bem como eventuais dificuldades com o bebê e com a amamentação ${ }^{21}$.

\section{Conclusão}

Vários são os fatores que interferem na amamentação adolescente e na ocorrência do desmame precoce. A situação conjugal da mãe adolescente, o apoio familiar e 
as informaçóes fornecidas pela equipe de saúde sobre o aleitamento materno e seus benefícios para a mãe e para o bebê podem funcionar tanto como fatores de risco para a ocorrência do desmame precoce quanto fatores de proteçáo para a ocorrência e permanência da amamentação do bebê.

Quanto ao desmame precoce, as principais variáveis que o favorecem são o retorno ao emprego ou a escola pela adolescente, a falta de qualidade no relacionamento conjugal, a introduçáo de alimentos e líquidos durante o período em que se recomenda a amamentação exclusiva (até os seis meses de idade do bebê), a falta de informaçôes sobre o tema ou mesmo a sobrecarga de informaçôes técnicas sobre essa prática. Destes, a oferta de líquidos e outros alimentos parece ser o principal fator causador do fenômeno. Isso ocorre, muitas vezes, por se pensar que o alimento provido pela mãe não é suficiente para o desenvolvimento do bebê. Por outro lado, a falta de informaçóes sobre os benefícios da amamentação para a mãe e para o bebê também contribui de maneira significativa para o desmame precoce.

Observou-se que, no referencial teórico empírico consultado, muitas máes, tanto adolescentes quanto adultas, queixaram-se de ter recebido informaçóes sobre amamentaçáo somente no período pós-parto. Recomenda-se que estas orientaçóes também devam ser passadas pelos profissionais de saúde durante o período pré-natal, pois esse momento parecer ser ideal para a troca de informaçóes entre gestante, pais e familiares. Além disso, percebe-se que as mães participantes de alguns estudos consultados pareciam não estar satisfeitas em relação à comunicação, por parte dos profissionais de saúde, sobre os benefícios da amamentação e o reconhecimento de dificuldades encontradas no ato de amamentar.

Isso pode levar as mães ao desconhecimento ou conhecimento insuficiente sobre alguns aspectos presentes na situação de amamentação, como: possíveis problemas na mama; possíveis técnicas de oferta; importância da amamentação para o estímulo do vínculo entre mãe e bebê; benefícios nutricionais, fonoaudiológicos, psicológicos e biológicos do leite materno para o desenvolvimento do bebê.

Um aspecto que pode influenciar positivamente no processo de amamentaçáo e é trazido pela literatura consultada ainda timidamente, é a participação e o envolvimento da figura paterna durante o aleitamento materno. Lembramos que o pai vem assumindo responsabilidades importantes para a qualidade desta vivência, apesar da amamentaçáo ainda estar fortemente vinculada à figura materna. $\mathrm{O}$ pai pode participar na busca de informaçôes e auxiliar a parceira a enfrentar as dificuldades encontradas no processo de amamentar.
Assim, conclui-se que é necessário desenvolver maneiras mais eficazes de distribuir informaçóes sobre o aleitamento materno que consigam atingir as mães de forma clara e objetiva. É importante reconhecer possíveis dificuldades no processo de aleitamento materno e utilizar técnicas de enfrentamento das mesmas, como a prevenção à fissura mamilar e ao empedramento do leite. As mães e os pais, sejam eles adolescentes ou adultos, devem ser conscientizados sobre as vantagens da amamentação e as desvantagens do desmame precoce para o desenvolvimento físico e psíquico do lactente. Porém, chama-se atenção para que estas informaçóes sejam transmitidas pelos profissionais de saúde, sempre levando em consideração a idade, as crenças e o contexto sociocultural desses indivíduos. A falta ou sobrecarga de informação pode levar à ocorrência do desmame precoce, muitas vezes porque as informaçôes são comunicadas de maneira pouco clara e de forma muito técnica, não se adequando à realidade da população que procura o atendimento.

Este estudo contribui na medida em que identifica os fatores que colaboram ou não para a ocorrência do desmame precoce. Isto torna viável o desenvolvimento de estratégias de prevenção e promoção de saúde neste contexto. Destaca-se a importância de pesquisas que busquem conhecer e entender o processo de aleitamento materno durante a adolescência, identificando variáveis que podem tornar bebês de mães adolescentes mais vulneráveis ao desmame precoce. $\mathrm{O}$ reconhecimento das vantagens da amamentação e as desvantagens do desmame precoce para o desenvolvimento físico e psíquico do lactente já se constitui como um forte argumento que justifica a relevância do tema e incentiva o desenvolvimento de estudos na área.

\section{Referências}

1. Dias AC, Teixeira MA. Gravidez na adolescência: um olhar sobre um fenômeno complexo. Paidéia. 2010;45(20):123-31.

2. Levandowsky DC, Piccinini CA, Lopes RCS. Maternidade adolescente. Estudos Psicol. 2008;25(2):251-63.

3. Patias ND, Jager ME, Fiorin PC, Dias ACG. Construção histórico social da adolescência: implicação na percepção da adolescência como um problema. Contexto e Saúde. 2011;10(20):205-14.

4. Andrade PR, Ribeiro CA, Ohara CVS. Maternidade na adolescência: sonho realizado e expectativas quanto ao futuro. Rev Gaucha de Enferm. 2009;30(4):662-8.

5. Esteves JR, Menandro PR. Trajetórias de vida: repercussóes da maternidade adolescente na biografia de mulheres que viveram tal experiência. Estudos Psicol. 2005;10(3):363-70.

6. Galvão MTG, Vasconcelos SG, Paiva SS. Mulheres doadoras de leite humano. Acta Paulist Enferm. 2006;19(2):157-61. 
7. Kummer SC, Giugliani ERJ, Susin LO, Folletto JL, Lermen NR, Wu VYJ, Santos L, Caetano MB. Evolução do padrão de aleitamento materno. Revi Saude Pública. 2000;34(2):143-8.

8. Falceto OG. Unidos pela amamentação. Porto Alegre: Da Casa; 2006.

9. Brasil. Ministério da Saúde. Secretária de Atenção à Saúde. Promovendo o aleitamento materno. Brasília: Total Editora; 2007.

10. King FS. Como ajudar as mães a amamentar. Brasília: Ministério da Saúde; 2001.

11. Frota DA, Marcopito LF. Amamentação entre mães adolescentes e não-adolescentes, Montes Claros, MG. Rev Saude Pública. 2004;38(1):85-92.

12. Bernardo WM, Nobre MRC, Janete FB. A prática clínica baseada em evidências. Parte II: buscando evidências em fontes de informação. Revi Assoc Méd Bras. 2004; 50(1):1-9.

13. Sepka GC, Gasparelo L, Silva AB, Mascarenhas TT. Promoçáo do aleitamento materno com mães adolescentes: acompanhando e avaliando essa prática. Cogitare Enferm. 2007;12(3):313-22.

14. Camarotti CM, Nakano AMS, Pereira CR, Medeiros CP, Monteiro JCS. Perfil da prática da amamentação em grupo de mães adolescentes. Acta Paulist Enferm. 2011;24(1):55-60.

15. Nunes JM, Oliveira EN, Vieira NFC. Concepçóes de puérperas adolescentes sobre o processo de amamentar. Rev Rede Enferm Nordeste. 2009;10(2):86-94.

16. Costa PJ, Locatelli BMES. O processo de amamentação e suas implicaçóes para a mãe e seu bebê. Mental. 2008;4(10):85-102.

17. Klein MMS, Guedes CR. Intervenção psicológica a gestantes: contribuiçóes do grupo de suporte para a promoção da saúde. Psicologia Cienc Prof. 2008;28(4):862-71.

18. Louzada VB. Amamentaçáo como um ato psicossocial [trabalho de conclusão de curso]. Governador Valadares: Universidade Vale do Rio Doce; 2008.

19. Lana APB. O livro de estímulo à amamentação. São Paulo; Atheneu: 2001.
20. Demitto MO, Silva TC, Páschoa ARZ, Mathias TAF, Bercini LO. Orientaçóes sobre amamentação na assistência pré-natal: uma revisão integrativa. Rev Rede Enferm Nordeste. 2010;11(n. esp.):223-9.

21. Kohler CVF. Vivências da adolescente no aleitamento materno e participaçáo de sua mãe nesse processo [dissertaçáo]. Porto Alegre: Universidade Federal do Rio Grande do Sul; 2005.

22. Silvestre PK, Carvalhares MABL, Venâncio SI, Parada CMGL. Conhecimentos e práticas de profissionais de saúde sobre o aleitamento materno em serviços públicos de saúde. Rev Lat Am Enferm. 2009;17(6).

23. Lacerda SMM, Maia ER. Aleitamento materno entre mães adolescentes: um estudo sobre desmame na atenção básica, Iguatu - CE. Cad Cult Cien. 2006;1(1):446-59.

24. Brasil. Ministério da Saúde. Secretária Executiva. Humanização do parto: humanização no pré-natal e nascimento. Brasília; 2002.

25. Moreira T, Viana DS, Queiroz MVO, Jorge MSB. Conflitos vivenciados pelas adolescentes com a descoberta da gravidez. Rev Esc Enferm. 2008;42(2):312-20.

26. Saes SO, Goldberg TBL, Ondani LM, Valarelli TP, Carvalho AP. Conhecimento sobre amamentação: comparação entre puérperas adolescentes e adultas. Rev Paulist Pediatr. 2006;24(2):121-6.

27. Silveira FJF, Lamounier JA. Fatores associados à duração do aleitamento materno em três municípios na região do Alto Jequitinhonha, Minas Gerais, Brasil. Cad Saude Pública. 2006;22(1):69-77.

28. Pontes CM, Alexandrino AC, Osório MM. Participação do pai no processo da amamentação. J Pediatr. 2008;84(4):357-64.

29. Piazzalunga CRC, Lamounier JA. A paternidade e sua influência no aleitamento materno. Pediatria. 2009;31(1):49-57.

30. Levandowski DC, Piccinini CA. Expectativas e sentimentos em relaçáo à paternidade entre adolescentes e adultos. Psicologia: Teoria e Pesquisa. 2006;22(1):7-28. 